\title{
Development of whey protein isolate films incorporated with rosemary extracts to improve the microbiological quality of fresh tuna
}

\begin{abstract}
The antibacterial activity of supercritical fluid extracts (SCFEs) of sage, oregano, garlic and rosemary was tested against 12 bacteria related with the spoilage of fish. Results show that rosemary SCFE was the most effective followed by garlic extract. Bacteria like S. epidermidis was the most sensitive. In addition, rosemary SCFE was included in whey protein isolate (WPI) films at three different concentrations and their antibacterial activity was also tested. WPI-rosemary films showed different activity clearly dependent on the concentration of extract and bacteria strain. S. putrefaciens was the most sensitive strain. When fresh tuna steaks (Thunnus alalunga) stored at refrigeration conditions were coated with WPI incorporated with 2 different concentrations of rosemary SCFE, the growth of microorganisms was inhibited especially aerobic mesophilic and Enterobacteriaceae. Whey protein edible films could be proposed as a preservation technology to improve the microbiological quality and food safety of fish products.
\end{abstract}

Keywords: antimicrobial agents, edible coatings, supercritical fluid extracts, whey protein isolate, fish preservation
Volume 5 Issue 2 - 2017

\author{
Ximena Carrión Granda,' Idoya Fernández \\ Pan, ${ }^{2}$ Bruno Iñarra, ${ }^{3}$ Susana Mezquita, ${ }^{3}$ Jordi \\ Rovira, ${ }^{4}$ Juan ' Maté ${ }^{5}$ \\ 'Viscofan SA R+D Department, Spain \\ ${ }^{2} \mathrm{BCC}$ Innovation, Basque Culinary Center, Spain \\ ${ }^{3}$ Food Sustainable Area, AZTI Tecnalia, Spain \\ ${ }^{4}$ Laboratorios CINFA SA, Spain \\ ${ }^{5}$ Department of Biotechnology and Food Science, Universidad \\ de Burgos, Spain \\ ${ }^{6}$ Department of Food Technology, Universidad Pública de \\ Navarra, Spain
}

Correspondence: Idoya Fernández Pan, BCC Innovation, Basque Culinary Center, Paseo Juan Avelino Barriola, I0I 20009 Donostia-San Sebastián, Spain, Tel 943-574-547, Fax 943-574502, Email ifernandez@bculinary.com

Received: October 29, 2017 | Published: November 14, 2017 
In recent years, supercritical fluid extraction (SFE), an environmental friendly and efficient extraction technique, has become an alternative to conventional extraction processes. SFE makes use of supercritical fluids to perform the extraction process. A fluid is considered to be in a supercritical state when the system pressure and temperature are above its critical point. ${ }^{11}$ At this region the gas and liquid phases become indistinguishable and the fluid has the unique ability to penetrate through solids like a gas and dissolve materials like a liquid.

Among others, $\mathrm{CO}_{2}$ is the most popular supercritical solvent because it is odourless, colourless, safe, readily available, non-toxic, non-flammable, recyclable and easy to remove from extracted products and has a low cost. ${ }^{11}$ Most of the substances related to the antimicrobial activity of essential oils, like carvacrol, thymol, camphor or borneol, are thermo labile. The use of SFE as an extraction technique would theoretically reduce the deterioration of such compounds, because the extraction process normally is performed at low temperatures. Currently, active edible coatings can be considered as an innovative technology to extend and guarantee the shelf life of especially fresh products. Many researchers are working in combining, for example, edible coatings (acting as a carrier) with antimicrobial/ antioxidant essential oils to reduce the growth of spoilage or pathogen microorganisms and extend the shelf life of food products. ${ }^{12-14}$ Many different biopolymers can form films including polysaccharides and proteins. In this study whey protein isolate (WPI), a biopolymer which forms flexible, odourless, tasteless and transparent films was used as carrier of natural antimicrobials.

The main objective of this work was to develop antimicrobial edible films to be applied to fish products. Therefore, first we developed and evaluated the antibacterial activity of different supercritical fluid extracts on the growth of microorganisms related with the spoilage and pathogen city of fish and seafood. The most effective SCFE were incorporated into whey protein isolated films and their antimicrobial activity was tested. Finally, the effect of the WPI films incorporated with two concentrations of rosemary SCFE on the microbial deterioration of tuna fish steaks under refrigerated storage was also evaluated.

\section{Materials and methods}

\section{Supercritical fluid extracts}

Supercritical fluid extracts (SCFEs) of sage (Salvia officinalis) (10\%), oregano (Origanus vulgaris) $(10 \%)$, garlic (Allium sativum) and rosemary (Rosmarinus officinalis) $(10 \%)$ were provided by Idoki SCF Technologies S.L. (Derio-Spain).

\section{Bacteria strains}

Twelve bacterial strains (Table 1) were used to evaluate the antimicrobial activity of extracts. All strains were supplied by the Spanish Type Culture Collection (CECT, Universidad de ValenciaSpain). After recuperation, bacterial strains were kept either under freezing storage in Eppendorf tubes containing a mix of Brain Heart Infusion broth with $30 \mathrm{~g} / 100 \mathrm{~mL}$ of glycerol or in cryovials with porous beads at $-80^{\circ} \mathrm{C}$.

\section{Other materials}

WPI was provided by Davisco Food International (Le Seur, MN,
USA). Glycerol was provided by Pancreas Química S.A. (BarcelonaSpain). Filter paper discs, Nutrient Broth I and Nutrient Broth II were provided by Oxoid (Barcelona-Spain), Trypticase Soy Broth and Trypticase Soy Agar, Brain Heart Infusion and Sodium Chlorine were provided by Merck (Madrid-Spain).

\section{Antibacterial activity of supercritical fluid extracts}

The disc diffusion method ${ }^{15}$ was used for screening the antibacterial activity of SCFEs against the 12 selected bacteria strains. Overnight cultures grown in the specific media for each bacterium were used. A filter paper disk $(6 \mathrm{~mm}$ diameter) soaked with $10 \mu \mathrm{l}$ of SCFE was placed on top of the agar plate inoculated with a loan of $10^{7} \mathrm{cfu} / \mathrm{ml}$ of each strain. Plates were incubated at the corresponding conditions (Table 1) for 24hours. All tests were performed in triplicate. The diameters of zones of inhibition were measured using a calliper and expressed as areas of inhibition in $\mathrm{mm}^{2}$ excluding the disc diameter

\section{Formulation of the Whey Protein Isolate films}

WPI films were prepared as follows: Whey protein isolate $(10 \%$ $\mathrm{w} / \mathrm{w})$ was dissolved in distilled water and $5 \%(\mathrm{w} / \mathrm{w})$ of glycerol was added as plasticizer. Then, film forming solutions (FFS) were heated using a thermostatic bath at $90^{\circ} \mathrm{C}$ during 30 minutes under constant stirring. The selected extracts were added at 1,3 and $5 \%(\mathrm{w} / \mathrm{w})$ once FFS were cooled at room temperature. The FFS were homogenized by sonication (UP 400S Hielscher Ultrasound Technology, Germany) using a $7 \mathrm{~mm}$ diameter tip for 5 minutes at $100 \%$ of amplitude and immersing FFS in an ice-water bath in order to avoid temperature raises over $30^{\circ} \mathrm{C}$. FFS were casted pouring $14 \mathrm{~g}$ onto glass dishes $(14 \mathrm{~cm}$ diameter) and dried overnight at room temperature and relative humidity.

\section{Antibacterial activity ofWPI films enriched with SCFE}

Same as for the case of SCFEs, the disc diffusion method was used to evaluate the antibacterial activity of WPI films against four bacteria strains: Aeromonas hydrophila, Shewanella putrefaciens, Vibrio alginolyticus and Pseudomonas fragi. In this case, discs of $17 \mathrm{~mm}$ diameter of every film formulation were cut using a punch and placed onto agar plates inoculated with an inoculum of $10^{7} \mathrm{cfu} / \mathrm{ml}$ of each strain. Plates were incubated under the conditions showed in Table 1 for 24 hours. All tests were performed in triplicate. The inhibition zone diameters were measured using a calliper and expressed as areas of inhibition in $\mathrm{mm}^{2}$ excluding the disc diameter.

\section{Fish sample preparation}

Fresh raw tuna steaks were provided by a local supplier and transported to the laboratory in a cooler filled with ice. Under sterile conditions, steaks were cut into pieces of $5 \times 3 \times 2 \mathrm{~cm}$ (length $\mathrm{x}$ width $\mathrm{x}$ height) and $30 \mathrm{~g}$ weight approximately. Cut steaks were randomly separated into 3 groups: the first one without any treatment used as control (CONTROL: C), and the other two groups were coated with the respectively FFS (WPI-Ros-3 for WPI+Rosemary $3 \%$ and WPIRos-4 for WPI+Rosemary 4\%). For coating, every piece was dipped in $100 \mathrm{ml}$ of FFS during 2minutes; then, the FFS excess was allowed to drip off for 30seconds and finally, pieces were dried under cool air stream for 45 seconds each side. Both control and coated samples were packaged in polypropylene trays, sealed with $\mathrm{PE} / \mathrm{PP} / \mathrm{EVOH} / \mathrm{PP}$ film without modified atmosphere and stored at $4{ }^{\circ} \mathrm{C}$ during 8 days. 
Table 1 Bacteria strains tested and growth conditions

\begin{tabular}{lllll}
\hline No. CECT & Bacteria & Gram & Culture medium & Incubation temp $\left({ }^{\circ} \mathbf{C}\right)$ \\
\hline 838 & Aeromonas caviae & - & Nutrient Broth I & 30 \\
5173 & Aeromonas hydrophila & - & Tripticase Soy Agar & 30 \\
194 & Enterobacter cloacae & - & Nutrient Broth I & 30 \\
173 & Morganella morganii & - & Nutrient Broth I & 37 \\
378 & Pseudomonas fluorescens & - & Nutrient Broth II & 26 \\
446 & Pseudomonas fragi & - & Nutrient Broth II & 26 \\
5346 & Shewanella putrefaciens & - & Nutrient Broth II & 26 \\
115 & Stenotrophomonas maltophila & - & Nutrient Broth II & 30 \\
521 & Vibrio alginolyticus & - & Nutrient Broth I $+3 \%$ NaCl & 26 \\
481 & Enterococcus faecalis & + & Brain Heart Infusion & 37 \\
232 & Staphylococcus epidermidis & + & Nutrient Broth II & 37 \\
236 & Staphylococcus warneri & + & Nutrient Broth II & 37
\end{tabular}

CECT, colección española de cultivos tipo.

\section{Microbiological analysis}

$25 \mathrm{~g}$ of sample was aseptically weighed, placed in a sterile plastic bag (Seward, UK) and homogenized with $225 \mathrm{ml}$ of buffered peptone water (Cultimed, Spain) using a stomacher (Stomacher 400 , England) for 2 minutes. Decimal dilutions were prepared as needed and seeded in the correspondent media in order to perform the following determinations: a) total viable counts (TVC) on pour plates of Plate Count Agar (PCA, Merck-Germany) incubated for 48 hours at $30^{\circ} \mathrm{C}$; b) total psychrotrophic bacteria on pour plates of Plate Count Agar (PCA, Merck-Germany) incubated for 7-10days at $4^{\circ} \mathrm{C}$; c) Enterobacteriaceae on double-layered pour plates of Violet Red Bile Glucose (VRBG, Cultimed-Spain) incubated for 24hours at $37^{\circ} \mathrm{C}$; d) Pseudomonas spp. on spread plates of Pseudomonas Agar Base (Oxoid-Spain) supplemented with Cetrimide-FucidineCephalosporine (CFC, Oxoid-Spain) incubated for 48 hour at $30^{\circ} \mathrm{C}$; and, e) lactic acid bacteria (LAB) on spread plates of de Man, Rogosa and Sharpe Agar (MRS, CONDA-Spain) incubated for 5 days at $30^{\circ} \mathrm{C}$. All plates were examined visually for typical colonies associated with each medium. Microbiological analyses were conducted at days 0 , $1,3,6$ and 8 of the storage period. All microbiological results are expressed as the log of the colony forming units (CFU) per gram of sample. All analyses were done in triplicate.

\section{Statistical analysis}

All tests were performed in triplicate. Statistical analyses were performed using SPSS 21.0 (IBM, USA) software. Significant differences among extracts were determined using ANOVA and Duncan's multiple range post hoc tests (confidence level of 95\%).

\section{Results and discussion}

\section{Antimicrobial activity of SCFEs}

The antimicrobial activity of SCFEs against the 12 bacteria strains related with the spoilage and pathogeni city of fish and seafood is presented in Table 2. In general, rosemary SCFE showed the largest zone of inhibition, followed by garlic SCFE; sage SCFE showed little or no activity and oregano SCFE showed the lowest inhibition zones. Regarding strains the Gram-negative P. fluorescens and E.cloacae were the most resistant bacteria (with the lowest inhibition area) and on the other hand A. caviae, M. morganii, S. epidermidis and V. alginolyticus the most sensitive. It is remarkable to mention that every bacteria strain showed different degrees of susceptibility for every SCFE tested.

Regarding rosemary extract, S. epidermidis was the most sensitive strain showed the largest inhibition area and on the other hand $P$. fluorescens and E. cloacae were the less susceptible strains. Many researchers have shown the effectiveness of rosemary essential oil (EO) or extract in the inhibition of different bacteria and are in accordance with our results, despite the absolute values of inhibition areas are not the same. Ivanovic $J$ et al. ${ }^{16}$ tested rosemary SCFE against bacteria like B. cereus, E. faecium, S. enteritidis or E. coli and found that the extract was more active against the Gram-positive bacteria than the Gram-negative ones. In the same line, Muñoz M et al. ${ }^{6}$ determined the effect of different plant SCFEs on the growth of $L$. monocytogenes and found that rosemary extract was the most effective (compared to oregano and laurel SCFE), reducing counts even below the detection limit. The activity or rosemary SCFE has been related with the presence of active compounds like carnosic acid, camphor, carnosol, borenol, 1,8-cineole, alfa-pinene. ${ }^{16,17}$ In their work Ramírez P et al. ${ }^{18}$ evaluated the antimicrobial activity of rosemary SCFE and the three different fractions obtained by SCF fractionation process; besides, the composition of the extract and every fraction collected was analysed by gas chromatography. They associated the activity of the extract with the carnosic acid content as they found that the fraction that was richer in (mainly composed by) carnosic acid presented the highest MIC against $S$. aureus and $E$. coli. Jordán MJ et al. ${ }^{17}$ showed in their research that high content of carnosol in relation to carnosic acid improved the antimicrobial activity of rosemary methanolic extracts against $L$. monocytogenes and $S$. aureus.

Garlic SCFE was also able to inhibit the growth of all strains tested. Bacteria like $M$. morganii or $V$. alginolyticus showed clear inhibition areas of 66.86 and $53.25 \mathrm{~mm}^{2}$ respectively. Some investigations have shown that extracts from garlic bulbs inhibit the growth of $V$. paraemolitycus, E. coli and other bacteria belonging to the Enterobacteriacea genera. ${ }^{4,19}$ Mahmoud BSM et al. ${ }^{19}$ found that garlic oil at $1 \%$ and $2 \%$ inhibited different strains isolated 
from carp fillets. Such activity has been attributed to the presence of thiosulfinates compounds including allicin, the main component of garlic. ${ }^{20}$ In their work, Zalepugin DY et al. ${ }^{21}$ tested different active compounds obtained from garlic SCFE and found that allicin showed weak antimicrobial activity against $P$. aurantiaca and E. coli and no activity against $B$. cereus. The active compound diallyl disulfide and trisulfide showed little activity against $B$. cereus and no activity against the two Gram-negative bacteria. Besides, they also tested synthetic disulfide and found that it had higher antimicrobial activity against $B$. cereus compared to the natural one. This could be explained by the thermal instability of all compounds present in garlic extracts.

Oregano SCFE showed very little or no activity against all bacteria strains tested. In the study presented by Mith $\mathrm{H}$ et al., ${ }^{22}$ oregano $\mathrm{EO}$ at different concentrations $(100 \%, 50 \%, 10 \%, 5 \%$ and $2.5 \%)$ was tested against $L$. monocytogenes. The EO at $100 \%$ inhibited the growth of the bacteria while when the concentration decreased at $50 \%$ or $10 \%$, the EO did not inhibit the growth of the aforementioned bacteria. In our study the concentration of the oregano SCFE was $10 \%$ and the poor activity of oregano SCFE could be attributed to the very low concentration tested. On the other hand, and despite some previous works have described the antibacterial activity of oregano SCFE against many bacteria, ${ }^{6,23}$ the lack of activity of oregano SCFE could be also related to the extraction process and the minimum concentration of active compounds like carvacrol or thymol. SCFE can contain, besides the active principles, some additional compounds like waxes, which could encapsulate these principles and diminish or even remove such activity. ${ }^{11}$ Furthermore, the extraction yield, and the percentage of active compounds present in the extract, could be affected by the particle size and the moisture content of the raw material. ${ }^{24}$

In the case of sage SCFE, there was no antimicrobial activity against most of the tested bacteria strains, except for $S$. putrefaciens and $S$. epidermidis, which were inhibited. On contrary, some previous studies have reported strong antibacterial activity for sage EO. ${ }^{9,25}$ As it was mentioned before $P$. fluorescens was one of the most resistant bacteria against all extracts except garlic SCFE. The results of the present study are in agreement with previous works in which the resistance of Pseudomonas spp. is documented. ${ }^{7,9,14}$ Such resistance is related to the nature of Pseudomonas spp.: they are Gram-negative bacteria and besides the cytoplasmic membrane, they have an outer membrane which is known to restrict the entrance of hydrophobic compounds acting therefore as a barrier against hydrophobic antimicrobial substances like EOs. For example, the high resistance of $P$. aeruginosa to antimicrobial compounds is attributed to the high $\mathrm{Mg}^{2+}$ content in the outer membrane, helping to produce strong lipopolysaccharide-lipopolysaccharide links and the small size of pores limit general diffusion. ${ }^{26}$ Despite $S$. putrefaciens, A. hydrophila and $V$. alginolyticus are Gram-negative bacteria, rosemary and garlic SCFE caused inhibition in their growth. Similar results have been shown by Gómez-Estaca $\mathrm{J}$ et al. ${ }^{14}$ and who found that these strains were totally or partially inhibited by clove, thyme or rosemary, among others EOs.

Despite literature attributing less resistance for the Gram-positive rather than Gram-negative bacteria against antimicrobial compounds, this research found a significant susceptibility of some of the tested Gram-negative strains. Same as our results, Sharififar F et al. ${ }^{27}$ also reported that the EO of Zataria multiflora Boiss inhibited the growth of some Gram-negative strains like S. typhi or S. flexneri. In her work, Burt $^{8}$ reported that such difference in susceptibility between Gram-positive and Gram-negative strains could be related to possible variations in composition of different batches of essential oils or extracts.

\section{Antibacterial activity of WPI films}

Rosemary SCFE was selected to be incorporated into the film formulation in order to test its antibacterial activity once included inside a film matrix. Such extract was selected due to its high antibacterial activity, compared with the other three extracts, as shown in the screening previously performed (Table 2).

A. hydrophila, S. putrefaciens, V. alginolyticus and P. fragi were selected in order to test the antimicrobial activity of WPI films. These bacteria have been largely studied and related with the spoilage and pathogen city of fish and seafood products. ${ }^{6,28}$

As it was expected, the higher the concentration of rosemary SCFE included in the WPI film, the greater the inhibition areas of the tested films. S. putrefaciens was the most sensitive bacteria, showing areas of inhibition even at $1 \%$ concentration of SCFE. A. hydrophila presented inhibition just at $5 \%$ concentration of rosemary SCFE. On the other hand and P. fragi was again the most resistant bacteria and WPI-enriched films did not inhibit its growth (Figure 1). GómezEstaca $\mathrm{J}$ et al. ${ }^{14}$ also found that $P$. fragi was the most resistant strain when tested gelatin-chitosan films with thyme EO.

The results of the antibacterial activity of WPI-rosemary SCFE enriched films are consistent with the literature. Ponce AG et al. ${ }^{29}$ formulated chitosan and carboxymethyl cellulose films and included in the formulation $1 \%$ of rosemary EO and found that such films inhibited the growth of L. monocytogenes and squash native microbiota. Morsy MK et al. ${ }^{30}$ tested pullulan films enriched with $1 \%$ and $2 \%$ of rosemary EO and concluded that films inhibited the growth of S. Typhimurium, L. monocytogenes, E. coli O157:H7 and $S$. aureus at both concentrations. Same as our results the higher the concentration of SCFE, the stronger the antimicrobial activity.

Tested as extract, rosemary exerted antimicrobial activity against A. hydrophila, S. putrefaciens, V. alginolyticus and P. fragi Table 2, but when rosemary was included in WPI films the inhibition areas decreased or even were absent. This reduction in activity could be associated with the degree of diffusivity of extracts when included into the matrix. In their research Royo $\mathrm{M}$ et al. ${ }^{5}$ tested sage $\mathrm{EO}$ added to filter paper discs and WPI and found that the EO had antimicrobial activity against $L$. innocua, $S$. enteritidis and $S$. aureus when included in filter paper discs but they did not have any activity when included in the biopolymer. They stated that this difference of activity could be related with the low diffusivity of the active compounds through the WPI matrix. They concluded that the antimicrobial effect depend on the matrix used and its ability to release active compounds. In the same line Fernández-Pan I et al. ${ }^{31}$ tested different essential oils as such and incorporated in WPI films and concluded that the lack or poor activity of WPI-EO enriched films could be attributed to the fact that the essential oils were not released from the matrix at the concentration needed to inhibit the growth of the bacteria.

\section{Microbiological changes on tuna steaks}

The changes in the microbiota of tuna steaks coated with FFS enriched with different concentrations of rosemary SCFE and stored 
at $4^{\circ} \mathrm{C}$ are shown in Figure 2A-2E. The initial value of TVC were low (around $3 \log \mathrm{fu} / \mathrm{g}$ ) implying acceptable quality and correct handling practices during processing of steaks. Similar low counts were observed in previous experiments with other fish species. ${ }^{14,32}$ In any case, TV final counts did not exceed $7 \log c f u / g$ during the storage period, which is the threshold value recommended by Foods ${ }^{33}$ for the commercialization of fresh water and marine species. As it was expected, counts in control samples significantly increased during the storage period. Same as for TVC, the initial population of Enterobacteriaceae was low (1.65logcfu/g) highlighting the good hygiene of tuna steaks.

Since day 3 for all microbial group analyzed, samples treated with WPI-Ros-3 and WPI-Ros-4 showed significant differences $(\mathrm{p}<0.05)$ compared with control samples. In the case of Pseudomonas, none of the treatments inhibited the growth of these bacteria. Between the two treatments, significant differences were observed depending mainly of type of microorganism analyzed concentration of SCFE and the storage day.

Edible coating containing $4 \%$ of rosemary SCFE was more effective in reducing the growth of TV microorganisms than the other treatments, as it can be observed in Figure 2A. At the end of the storage period a difference in counts of $1 \log \mathrm{g} f \mathrm{fu} / \mathrm{g}$ was observed when compared with $\mathrm{C}$ samples. In the case of WPI-Ros-3 smaller but significant difference of $0.5 \log \mathrm{cfu} / \mathrm{g}$ was observed, always compared with the $\mathrm{C}$ samples. WPI-Ros-3 and WPI-Ros-4 also reduced significantly $(\mathrm{p}<0.05)$ the TV counts at day 6 of storage. In their study, Gómez-Estaca $\mathrm{J}$ et al. ${ }^{34}$ coated cold-smoked sardine with gelatin coatings incorporated with rosemary EO and stored for 20days at $5^{\circ} \mathrm{C}$. At day 16 of storage TVC were also reduced in about $1.5 \operatorname{logcfu} / \mathrm{g}$, Table 2 Inhibitory areas ( $\mathrm{mm}^{2}$, excluding disc area) of SCFE against different bacteria strains. Letters a-c show significant differences among SCFEs. Letters A-E show significant differences among strains $(p<0.05)$

\begin{tabular}{lllll}
\hline Bacteria & S-SCFE & Or-SCFE & Gar-SCFE & Rg-SCFE \\
\hline Aeromonas caviae (-) & $1.3^{\mathrm{aAA}}$ & $0.26^{\mathrm{aA}}$ & $35.85^{\mathrm{bB}}$ & $99.56^{\mathrm{cE}}$ \\
Aeromonas hydrophila (-) & $0.1^{\mathrm{3aA}}$ & $1.83^{\mathrm{aC}}$ & $25.91^{\mathrm{bB}}$ & $50.76^{\mathrm{cBC}}$ \\
Enterobacter cloacae (-) & $0.13^{\mathrm{aA}}$ & $0.92^{\mathrm{aABC}}$ & $8.90^{\mathrm{bA}}$ & $0.26^{\mathrm{aA}}$ \\
Morganella morganii (-) & $0.26^{\mathrm{aA}}$ & $1.44^{\mathrm{aBC}}$ & $66.86^{\mathrm{cD}}$ & $48.80^{\mathrm{bBC}}$ \\
Pseudomonas fluorescens (-) & $3.27^{\mathrm{aA}}$ & $0.26^{\mathrm{aA}}$ & $35.85^{\mathrm{bB}}$ & $0.65^{\mathrm{A}}$ \\
Pseudomonas fragi (-) & - & - & - & $37.03^{\mathrm{aB}}$ \\
Shewanella putrefaciens (-) & $46.58^{\mathrm{bC}}$ & $0.7^{\mathrm{aABC}}$ & $37.29^{\mathrm{bB}}$ & $71.57^{\mathrm{CD}}$ \\
Stenotr. maltophilia (-) & $3.01^{\mathrm{aA}}$ & $0.13^{\mathrm{aA}}$ & $37.81^{\mathrm{bB}}$ & $3.53^{\mathrm{aA}}$ \\
Vibrio alginolyticus (-) & $3.01^{\mathrm{aA}}$ & $1.05^{\mathrm{aABC}}$ & $53.25^{\mathrm{bC}}$ & $76.28^{\mathrm{cD}}$ \\
Enterococcus faecalis (+) & $0.39^{\mathrm{aA}}$ & $0.39^{\mathrm{aAB}}$ & $28.52^{\mathrm{bB}}$ & $64.37^{\mathrm{cCD}}$ \\
Staphylococcus epidermidis (+) & $27.61^{\mathrm{bB}}$ & $0.13^{\mathrm{aA}}$ & $25.91^{\mathrm{bB}}$ & $130.70^{\mathrm{cE}}$ \\
Staphylococcus warneri (+) & $1.44^{\mathrm{aA}}$ & $0.13^{\mathrm{aA}}$ & $26.43^{\mathrm{bB}}$ & $77.06^{\mathrm{cD}}$ \\
\hline
\end{tabular}

S-SCFE, sage SCFE (10\%) dissolved in glycerin; Or-SCFE, oregano (10\%) SCFE dissolved in glycerin; Gar-SCFE, garlic SCFE; Rg-SCFE, rosemary SCFE (I0\%) dissolved in glycerin.

As it was mentioned before, none of the treatments could inhibit the growth of Pseudomonas. High initial counts (5logefu/g) were registered (Figure 2E). At the end of the storage period Pseudomonas spp. became the dominant group in tuna steaks with final counts of $9 \log \mathrm{cfu} / \mathrm{g}$. Fernández-Saiz $\mathrm{P}$ et al. ${ }^{35}$ also found Pseudomonas as a prevalent group in sole fillets stored under refrigeration. This lack though at the end of the storage period no reductions were observed.

Regarding $\mathrm{LAB}$, edible coatings exerted their antimicrobial effect from day 3 of storage and on (Figure 2B). Reduction of about $1 \log \mathrm{cfu} / \mathrm{g}$ was observed for both treatments when compared with control samples. At the end of storage period (day 8) just WPI-Ros-4 significantly $(\mathrm{p}<0.05)$ inhibited the growth of this microorganisms. Final counts of LAB for C and WPI-Ros-3 were around $6 \operatorname{logcfu} / \mathrm{g}$.

Counts of Enterobacteriaceae are shown in Figure 2C. As it was mentioned before, low initial counts of this bacteria $(1.65 \mathrm{logcfu} / \mathrm{g})$ indicates adequate practices during degutting, filleting and handling of tuna steaks. Data showed significant differences $(p<0.05)$ between treated and control samples. Differences in counts (compared with control samples) of 1 and $0.5 \log \mathrm{cfu} / \mathrm{g}$ were observed for WPI-Ros-4 and WPI-Ros-3, respectively, at the end of the storage period. Similar behavior was observed at day 3 of storage. During the rest of the storage period, no inhibition was observed.

The evolution of psychrotrophic bacteria during the storage period is showed in Figure 2D. Both treatments inhibited the growth of this bacteria observing significant $(\mathrm{p}<0.05)$ reductions in counts of $1.5 \log \mathrm{gfu} / \mathrm{g}$ at day 8 of analysis, compared with control samples. During the storage, no significant differences were observed between WPI-Ros-3 and WPI-Ros-4 until day 8 when WPI-Ros-4 was more effective in inhibited the growth of psychrotrophic bacteria. Same as our results, Abdollahi $\mathrm{M}$ et al. ${ }^{13}$ reported reductions of $1.5 \mathrm{logcfu} / \mathrm{g}$ of psychrotrophic bacteria at the end of the refrigerated storage period (16days) in silver carp fillets coated with chitosan/clay biopolymer incorporated with rosemary essential oil. 
coatings over these bacteria could be related with high counts since the beginning of the experiment. High numbers of Pseudomonas spp. could require higher concentration of rosemary SCFE to be inhibited.

Some previous studies have also pointed out the effectiveness of rosemary essential oil or extract included in different edible coatings in inhibiting the growth of natural microbiota present in food products. Morsy MK et al. ${ }^{30}$ found reductions in counts of L. monocytogenes and $S$. aureus inoculated in RTE turkey deli meat coated with pullulan films enriched with $2 \%$ of rosemary $\mathrm{EO}$, stored at $4{ }^{\circ} \mathrm{C}$ and vacuum packed. Liu Q et al. ${ }^{37}$ found that CMC films enriched with rosemary extract inhibited the growth of TVC on fresh beef refrigerated at $4^{\circ} \mathrm{C}$. Contrary to our results, Giménez B et al ${ }^{38}$ did not observe any reduction in TV counts when treated sea bream fillets with rosemary EO.

The antimicrobial activity of rosemary extract has been discussed before. It is related with the presence of carnosic acid, carnosol and rosmarinic acid, which are phenolic diterpenes containing a phenolic group in their structure. The mechanism associated at the antimicrobial activity of diterpenes is still not clear. It has been suggested that the ability of the hydrophobic structure of diterpenes enables them to partition the lipids of the bacterial cell membrane, making it more permeable. ${ }^{39}$

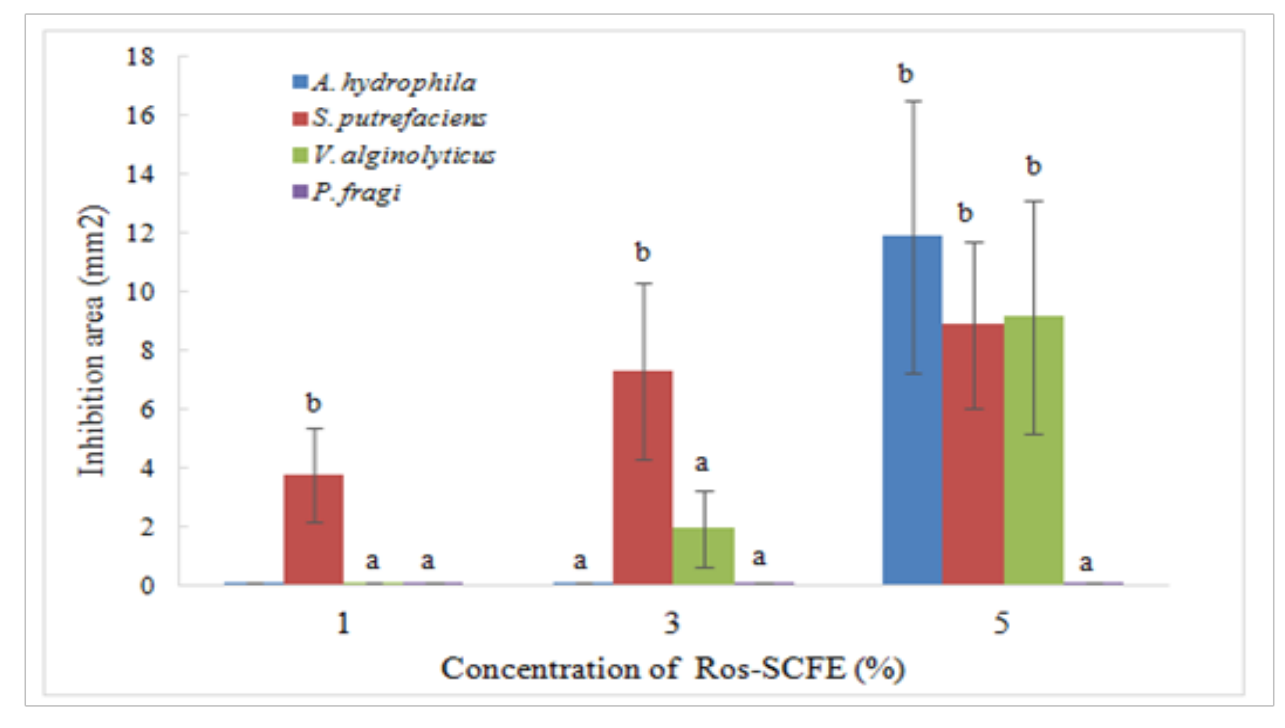

Figure IInhibitory areas ( $\mathrm{mm}^{2}$, excluding film area) of WPI films enriched with rosemary SCFE against A.hydrophila, S. putrefaciens, V. alginolyticus, and P. fragi. Different letters mean significant differences among concentration of SCFE $(p<0.05)$.

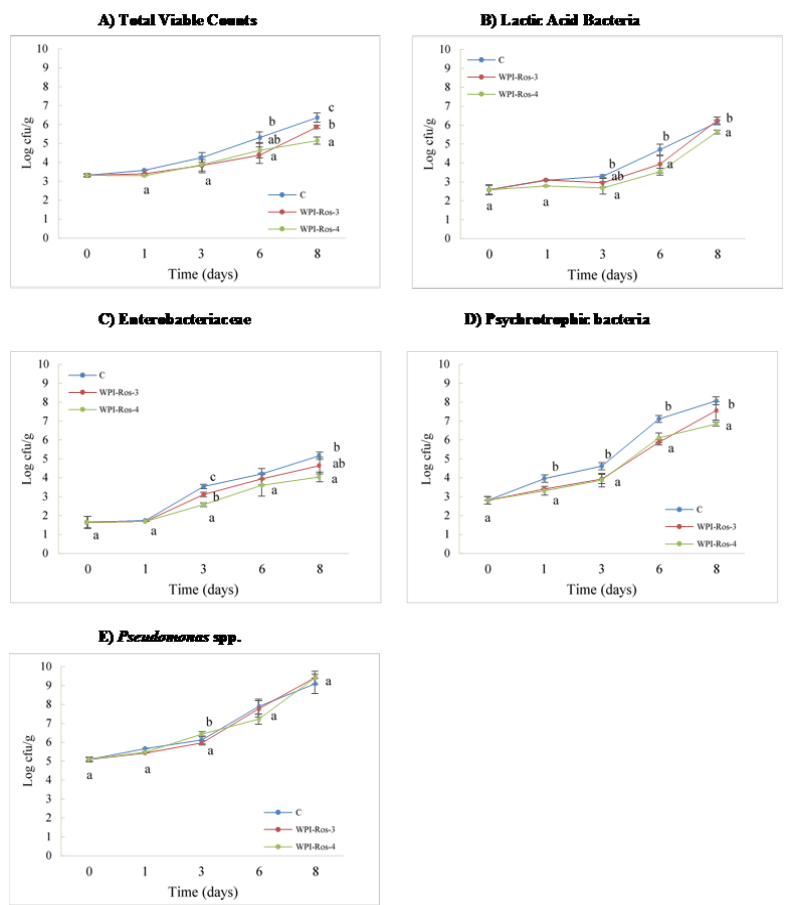

Figure 2 Evolution of the natural microbiota of WPI-ROS coated tuna steaks. C: Control;WPI-Ros-3:WPI+Rosemary SCFE 3\%;WPI-Ros-4:WPI+Rosemary SCFE 4\%. Different letters mean differences among treatments in the same day and bacterial group $(p<0.05)$. 


\section{Conclusion}

After performing the antimicrobial screening of the different supercritical fluid extracts, rosemary SCFE showed the highest antibacterial activity against the 12 spoilage and pathogenic bacteria strains tested, followed by garlic SCFE. P. fluorescens and E. cloacae were the most resistant strains. Rosemary SCFE was successfully incorporated in the WPI formulations at three different concentration and films showed different antimicrobial activity that was clearly dependent of the concentration of extract included and the susceptibility of the bacteria strain tested. S. putrefaciens was the most sensitive bacteria strain while the most resistant was $P$. frag $i$ which could not be inhibited for any of the formulated films. Then, the resistance of Pseudomonas spp. to the action of plant extracts was confirmed. WPI coatings incorporated with $4 \%$ rosemary SCFE have proven to help the preservation of fresh tuna steaks, inhibiting the growth of the natural microbiota present in the product. Therefore, the use of WPI films as carriers of natural compounds could control fish and seafood spoilers and pathogens and extend the shelf-life of fresh fish stored under refrigeration conditions.

\section{Acknowledgements}

None.

\section{Conflicts of interest}

The author declares no conflict of interest.

\section{References}

1. Ministerio de Agricultura AyMA. La alimentación mes a mes. Madrid: Ministerio de Agricultura, Alimentación y Medio Ambiente. Secretaría General Técnica; 2014.

2. Adams MR, Moss MO. Food Microbiology. 3rd ed. Cambridge, the Royal Society of Chemistry, Guildford, UK: University of Surrey; 2008. p. 1-478.

3. Gram L, Huss HH. Microbiological spoilage of fish and fish products. Int J Food Microbiol. 1996;33(1):121-137.

4. Yano Y, Satomi M, Oikawa H. Antimicrobial effect of spices and herbs on Vibrio parahaemolyticus. Int J Food Microbiol. 2006;111(1):6-11.

5. Royo M, Fernandez-Pan I, Mate JI. Antimicrobial effectiveness of oregano and sage essential oils incorporated into whey protein films or cellulosebased filter paper. J Sci Food Agric. 2010;90(9):1513-1519.

6. Muñoz M, Guevara L, Palop A, et al. Determination of the effect of plant essential oils obtained by supercritical fluid extraction on the growth and viability of Listeria monocytogenes in broth and food systems using flow cytometry. LWT-Food Science and Technology. 2009;42(1):220-227.

7. Lambert RJW, Skandamis PN, Coote PJ, et al. A study of the minimum inhibitory concentration and mode of action of oregano essential oil, thymol and carvacrol. J Appl Microbiol. 2001;91(3):453-462.

8. Burt S. Essential oils: Their antibacterial properties and potential applications in foods-A review. Int J Food Microbiol. 2004;94(3):223-253.

9. Bozin B, Mimica-Dukic N, Samojlik I, et al. Antimicrobial and antioxidant properties of Rosemary and Sage (Rosmarinus officinalis L. and Salvia officinalis L., Lamiaceae) essential oils. J Agric Food Chem. 2007:55(19):7879-7885.

10. Sokovic M, Glamocilija J, Marin PD, et al. Antibacterial effects of the essential oils of commonly consumed medicinal herbs using an in vitro model. Molecules. 2010;15(11):7532-7546.
11. Rosa P, Parajo J, Dominguez H, et al. Supercritical and pressurized fluid extraction applied to the food industry. In: Meireles MA editor. Extracting Bioactive Compounds for Food Products. 1st ed. Boca Raton: USA: CRC Press; 2009. p. 269-401.

12. Zinoviadou KG, Koutsoumanis KP, Biliaderis CG. Physico-chemical properties of whey protein isolate films containing oregano oil and their antimicrobial action against spoilage flora of fresh beef. Meat Sci. 2009;82(3):338-345.

13. Abdollahi M, Rezaei M, Farzi G. Influence of chitosan/clay functional bionanocomposite activated with rosemary essential oil on the shelf life of fresh silver carp. International Journal of Food Science and Technology. 2014;49(3):811-818

14. Gómez-Estaca J, López de Lacey A, López-Caballero ME, et al. Biodegradable gelatin-chitosan films incorporated with essential oils as antimicrobial agents for fish preservation. Food Microbiol. 2010;27(7):889-896.

15. NCCLS. Performance standards for antimicrobial disk susceptibility tests. Approved standard, 8th ed. Document M2-A8. Wayne, Pa: NCCLS; 2003

16. Ivanovic J, Misic D, Zizovic I, et al. In vitro control of multiplication of some food-associated bacteria by thyme, rosemary and sage isolates. Food Control. 2012;25(1):110-116.

17. Jordán MJ, Lax V, Rota MC, et al. Relevance of carnosic acid, carnosol, and rosmarinic acid concentrations in the in vitro antioxidant and antimicrobial activities of rosmarinus officinalis (L.) methanolic extracts. J Agric Food Chem. 2012;60(38):9603-9608.

18. Ramirez P, Garcia-Risco MR, Santoyo S, et al. Isolation of functional ingredients from rosemary by preparative-supercritical fluid chromatography (Prep-SFC). J Pharm Biomed Anal. 2006;41(5):16061613.

19. Mahmoud BSM, Yamazaki K, Miyashita K, et al. Bacterial microflora of carp (Cyprinus carpio) and its shelf-life extension by essential oil compounds. Food Microbiology. 2004;21(6):657-666.

20. Kyung KH. Antimicrobial properties of allium species. Curr Opin Biotechnol. 2012;23(2):142-147.

21. Zalepugin DY, Tilkunova NA, Yashin YS, et al. Application of supercritical fluid extraction to the development of new potential biocides on the basis of garlic (Allium sativum L.). Russian Journal of Physical Chemistry B. 2010;4(7):1103-1111.

22. Mith H, Dure R, Delcenserie V, Z et al. Antimicrobial activities of commercial essential oils and their components against food-borne pathogens and food spoilage bacteria. Food Sci Nutr. 2014;2(4):403-416.

23. Stamenic M, Vulic J, Djilas S, et al. Free-radical scavenging activity and antibacterial impact of Greek oregano isolates obtained by SFE. Food Chem. 2014;165:307-315.

24. Capuzzo A, Maffei ME, Occhipinti A. Supercritical fluid extraction of plant flavors and fragrances. Molecules. 2013;18(6):7194-7238.

25. Ozkan G, Sagdic O, Gokturk RS, et al. Study on chemical composition and biological activities of essential oil and extract from Salvia pisidica. $L W T$ Food Science and Technology. 2010;43(1):186-190.

26. Russel AD. Mechanisms of action, resistance, and stress adaptation. In Davidson PM, et al. editors. Antimicrobials in Foods. 3rd ed. Boca Raton, USA: CRC Press; 2005. p. 633-657.

27. Sharififar F, Moshafi MH, Mansouri SH, et al. In vitro evaluation of antibacterial and antioxidant activities of the essential oil and methanol extract of endemic Zataria multiflora Boiss. Food Control. 2007;18(7):800 805 . 
28. Gram L, Dalgaard P. Fish spoilage bacteria-problems and solutions. Curr Opin Biotechnol. 2002;13(3):262-266.

29. Ponce AG, Roura SI, del Valle CE, et al. Antimicrobial and antioxidant activities of edible coatings enriched with natural plant extracts: In vitro and in vivo studies. Postharvest Biology and Technology. 2008;49(2):294300 .

30. Morsy MK, Khalaf HH, Sharoba AM, et al. Incorporation of Essential oils and nanoparticles in pullulan films to control foodborne pathogens on meat and poultry products. Journal of Food Science. 2014;79(4):M675-684.

31. Fernández-Pan I, Royo M, Maté JI. Antimicrobial activity of whey protein isolate edible films with essential oils against food spoilers and foodborne pathogens. J Food Sci. 2012;77(7):M383-390.

32. Fernández-López J, Zhi N, Aleson-Carbonell L, et al. Antioxidant and antibacterial activities of natural extracts: Application in beef meatballs. Meat Sci. 2005;69(3):371-380.

33. Foods ICoMSf. Microorganisms in Foods 7. Microbiological testing in food safety management. London, UK: Kluwer Academic; 2002.

34. Gomez-Estaca J, Montero P, Gimenez B, et al. Effect of functional edible films and high pressure processing on microbial and oxidative spoilage in cold-smoked sardine (Sardina pilchardus). Food Chemistry. 2007;105(2):511-520
35. Fernandez-Saiz P, Sanchez G, Soler C, et al. Chitosan films for the microbiological preservation of refrigerated sole and hake fillets. Food Control. 2013;34(1):61-68.

36. Emiroglu ZK, Yemis GP, Coskun BK, et al. Antimicrobial activity of soy edible films incorporated with thyme and oregano essential oils on fresh ground beef patties. Meat Sci. 2010;86(2):283-288.

37. Liu Q, Han J, Zhang Y, et al. Antimicrobial and antioxidant activities of carboxymethyl cellulose edible films incorporated with rosemary extracts on fresh beef during refrigerated storage. Advanced Materials Research. 2012. p. 1187-1194.

38. Gimenez B, Roncales P, Beltran JA. The effects of natural antioxidants and lighting conditions on the quality characteristics of gilt-head sea bream fillets (Sparus aurata) packaged in a modified atmosphere. Journal of the Science of Food and Agriculture. 2004;84(9):1053-1060.

39. Cowan MM. Plant products as antimicrobial agents. Clin Microbiol Rev. 1999;12(4):564-582. 